\title{
A PRODUÇÃO DE INFORMAÇÃO E CONHECIMENTO Fundação de Economia e Estatística
}

José Antônio Fialho Alonso

\begin{abstract}
Resumo: A informação e o conhecimento sempre foram elementos estratégicos no desenvolvimento da humanidade, tendo sido fatores relevantes em todas as revoluções tecnológicas, e assumido, nesta última, o caráter de revolução da própria informação. Neste texto, são discutidos o modo de produção de estatísticas e do conhecimento e os veículos de disseminação mais utilizados.

Palavras-chave: produção de estatísticas; produção do conhecimento; organização e divulgação de informações.
\end{abstract}

Abstract: Information and knowledge have always been fundamental to human development, strategically present in all technological revolutions. In the most recent revolution, the very nature of information itself was redefined. Also examined is how statistics and knowledge are produced and most commonly disseminated.

Key words: statistical production; production of knowledge; organization and dissemination of information.

$\mathrm{A}$ informação e o conhecimento lato-sensu constituem insumos dos mais estratégicos para o desenvolvimento de qualquer sociedade, em qualquer tempo. Mais ainda, a relevância desses elementos tem sido crescente ao longo da história da civilização. Por essa mesma razão, experimentou e impôs ao mesmo tempo, às atividades que delas fazem uso, importantes avanços técnicos que, em geral, resultam em elevação da eficiência delas.

O objeto deste artigo é discutir como e para quem são produzidas a informação e o conhecimento. Além disso, busca examinar como são veiculados estes dois elementos até chegarem a seus usuários, bem como se ocupa da questão de saber qual o atual "estado das artes" neste tipo de atividade. No caso, parte-se do entendimento de que a informação reporta-se a dados numéricos e a indicadores, e o conhecimento, especificamente, aos estudos sobre a realidade socioeconômica.

Esta temática será tratada sob a óptica de uma instituição pública, a Fundação de Economia e Estatística (FEE), entidade cujo papel é organizar e difundir informações socioeconômicas referentes ao Estado do Rio Grande do Sul, bem como realizar estudos que têm como objeto a realidade gaúcha. Trata-se de uma atividade que, na divisão do trabalho no âmbito do setor público, passou por várias transformações em sua modelagem ao longo da história até chegar à atual estrutura organizacional e de funcionamento. $\mathrm{O}$ texto é composto de uma breve síntese da evolução histórica da atividade no setor público do Estado do Rio Grande do Sul e de um debate sobre a produção contemporânea de informação e do conhecimento em âmbito regional, seguido das usuais considerações finais.

\section{ASPECTOS HISTÓRICOS DA PRODUÇÃO DE ESTATÍSTICAS NO RIO GRANDE DO SUL}

A preocupação com a produção de estatísticas no Rio Grande do Sul é muito antiga, que remonta aos governos provinciais, tal como bem evidencia esta citação do Resumo Histórico da Estatística no Rio Grande do Sul (1969): "Hum fim tão magestoso não se consegue somente com simples nomenclaturas e collecçoens de quadros, mas sim adiccionando arrosoamentos e reflexões scientificas, fundadas em factos, e doutrinas, que conduzirão ao conhecimento evidente de todos os elementos políticos, e a melhor maneira de tirar d'elles a maior vantagem possível 
para o Estado Social (Da Quinta Memória, por José Gonçalves Chaves, divulgada em 1822)."

Na verdade, já antes desta data, em 1790, o Governo Provincial havia determinado a realização de um levantamento do número de capatazes, peões, carros, animais domésticos, escravos e tropas espalhadas pelo continente, além das sementes e da colheita de trigo do período 1783-89. Outros levantamentos foram realizados em 1801 e 1805 abarcando diferentes atividades, como as exportações e as importações. Esses trabalhos tiveram grande repercussão entre os "homens graduados do governo e entre os estudiosos da matéria", do que resultou em 1822 , a apresentação de uma proposta para a área de estatística, contida no documento: "Sugestões sobre a organização da estatística da Província de São Pedro do Rio Grande do Sul”, elaborado por Francisco Xavier Ferreira. Em 1833 já estavam lançadas as bases da organização estatística da Província do Rio Grande do Sul, materializada na criação do Serviço de Estatística da Província, pelo Governo Provincial.

Não obstante esses avanços, as atividades de organização e disseminação de informações estavam longe de constituir um "mar de rosas". Na verdade, os períodos de instabilidade política e financeira e a incompreensão demonstrada por alguns dirigentes estabeleceram, em vários momentos, um clima de desestímulo e enfraquecimento do setor, exigindo dos envolvidos com a questão um esforço redobrado para manter essa atividade na administração pública da época.

O Regime Republicano estabelecido a partir de 1889 estabeleceu novas condições para que a estatística riograndense pudesse contar com uma atmosfera propícia para seu desenvolvimento. Assim, um dos primeiros atos do Visconde de Pelotas ao assumir o Governo Estadual, foi a criação da Repartição de Estatística (29/12/1889). Nas décadas seguintes, o setor de estatísticas passou por diversas modificações a fim de ajudá-lo às necessidades impostas pela organização do Estado regional. ${ }^{2}$ Um avanço importante foi registrado a partir de 1926, com a criação de uma rede de informações e a nomeação de um delegado por cidade, a fim de coletar os dados com as próprias fontes, sendo o sistema regulado por convênios firmados entre o Governo do Estado e o dos municípios. Alguns anos mais tarde, o próprio IBGE implantaria uma organização muito semelhante.

Os anos 30 foram marcados por muitos recuos e avanços na área das estatísticas, tanto no Estado como no Brasil. Assim, praticamente até 1937, a repartição estadual viu-se na contingência de quase ter de paralisar suas atividades por falta de recursos. Todavia, a demanda por informações é algo sempre crescente, seja na crise, seja na prosperidade, o que levou o Interventor Cordeiro de Faria a retomar a atividade com a alocação de novos equipamentos ${ }^{3}$ e a contratação de funcionários, além de promover a vinda de um técnico do $\mathrm{IBGE}^{4}$ para trabalhar na padronização das estatísticas regionais. Outro fato marcante, neste final da década de 30 foi a transformação da Repartição de Estatística no Departamento Estadual de Estatística - DEE $^{5}$ (Decreto ${ }^{\circ} 8.006$, de 7/11/1939), criando assim um órgão que perduraria até o início dos anos 70. O DEE funcionou tecnicamente sob a égide do IBGE em todos os inquéritos deste período.

O final dos anos 60, em meio à euforia do "milagre", o DEE passa a integrar a Secretaria de Coordenação e Planejamento - SCP, recebendo investimentos e melhores instalações e equipamentos, mas ainda em volume insuficiente diante de demandas colocadas pela nova conjuntura. Desde então, as mudanças foram muito rápidas. No espaço de, aproximadamente um ano, o DEE foi extinto $(1972)^{6}$ e estabeleceu-se a forma institucional existente até hoje, a de uma Fundação para gerir a área das estatísticas e, adicionalmente, desenvolver estudos de natureza socioeconômica sobre o Rio Grande do Sul.

O novo formato institucional (administração indireta) acabou favorecendo o desenvolvimento de um ambiente caracterizado por maior flexibilidade na condução das atividades de análise econômica e organização das estatísticas do Estado do Rio Grande do Sul, embora certamente a conjuntura política da época (1973) não fosse considerada a mais adequada para consolidar qualquer trabalho de reflexão mais crítica. A nova fase de produção de estatísticas, acrescida com a atividade de produção de conhecimento no campo socioeconômico, teve sua formação viabilizada pela aglutinação de um quadro ainda jovem de pesquisadores na área de análise econômica e de um grupo de servidores experientes na organização de informações, todos dispondo apenas de formação acadêmica básica, o que explica os resultados relativamente incipientes alcançados nos trabalhos pioneiros que marcaram os primeiros anos de vida da FEE.

Do ponto de vista da estrutura administrativa, o organograma da instituição passou por várias modificações ao longo de seus 28 anos de existência, sempre com vista em adaptar-se às novas exigências impostas, tanto pelas demandas por seus serviços, quanto pelas desafiadoras possibilidades associadas às novas tecnologias. Ain- 
da assim, permaneceu sempre administrada por duas diretorias, uma técnica e uma administrativa, além da presidência. A produção da área das estatísticas e a da área de análise são dependentes da diretoria técnica, a qual está estruturada, no presente momento, em três supervisões e 15 núcleos.

\section{PRODUÇÃO CONTEMPORÂNEA DE INFORMAÇÃO E CONHECIMENTO}

Neste item será discutido o modo como são produzidas e organizadas as estatísticas na instituição e também a forma pela qual se dá produção cognitiva sobre a complexa realidade socioeconômica, com ênfase na dinâmica regional, vis-à-vis a nacional e internacional. Serão também abordadas as múltiplas formas presentemente utilizadas na disseminação das informações e do conhecimento acumulado, bem como um breve comentário a respeito dos tipos de usuários e a forma como são demandados estes produtos e serviços.

Antes, porém, cabe um rápido registro a respeito das profundas mudanças ocorridas, ao longo dos anos 90, nos processos de trabalho adotados na FEE, tal como se verificou, de resto, nas demais instituições congêneres. Essas mudanças foram processadas no bojo da introdução da microinformática e dos impressionantes avanços técnicos que marcaram o campo das telecomunicações, resultando em importantes modificações quanto às exigências na composição do quadro técnico da instituição. ${ }^{7}$ Nesse sentido, é crescente a substituição da mão-de-obra intermediária - auxiliares de pesquisa - por uma combinação de pesquisadores/estagiários de nível universitário e uma constelação de equipamentos de microinformática e softwares. Os resultados medem-se como elevação generalizada de produtividade e também de melhoria da qualidade dos produtos.

De forma mais concreta, pode-se observar que a FEE trabalha com dois conjuntos de informações. $\mathrm{O}$ primeiro, caracterizado por volume maior de registros, é formado por dados secundários, procedentes dos mais diversos órgãos públicos das três esferas de governo e também de algumas empresas privadas. São informações geradas ao mesmo tempo em que as organizações realizam sua produção e prestam serviços à sociedade. Para estas últimas, trata-se de dados primários, caracterizando-se como secundários para a FEE. Está-se fazendo referência aqui à grande massa de informações produzidas pelas Secretarias da Educação, da Saúde e Fazenda, em especial, e por órgãos da administração indireta nas áreas de agropecuária, energia elétrica ${ }^{8}$ e saneamento, entre outros. ${ }^{9}$ No plano Federal há, pelo menos, duas fontes relevantes de informações secundárias: o Instituto Brasileiro de Geografia e Estatística (IBGE) e o Ministério do Trabalho e Previdência Social. Grande parte destas informações tem como menor base espacial o município, o que permite chegarse a múltiplas agregações regionais.

O processo de recebimento de grandes volumes de dados pela FEE é potencializado pela crescente transferência de arquivos sob forma digital, em meio magnético (disquete, CD-ROM), pelo acesso indiscriminado aos bancos de dados e sites da WEB e, ainda, pelo serviço de correio eletrônico. Isso permitiu eliminar etapas e facilitou enormemente o trabalho anterior à divulgação da informação sistematizada. ${ }^{10}$ De posse dos referidos arquivos, inicia-se um paciente exame e a crítica das informações, com a finalidade de depurar e evitar o repasse de eventuais erros ou inconsistências estatísticas, cuja origem remonta, com freqüência, às próprias fontes. ${ }^{11} \mathrm{Na}$ verdade, é um trabalho de "limpeza" dos dados. Para tanto, recorre-se a comparações com séries passadas para aumentar o grau de confiabilidade e a consistência da informação. Há mesmo casos em que, ao final, resulta ser preferível não divulgar a informação recebida, em razão de sua inconsistência ou da incapacidade de a mesma representar devidamente o fenômeno expresso. Um exemplo pode tornar mais claro o que está sendo afirmado: tome-se a variável "posto de atendimento médico (PAM)" por município. Ela era registrada, em sua origem, como o número de PAMs existentes, o que, por si só, já introduz um problema conforme a representatividade da variável, uma vez que os postos variam quanto aos seus tamanhos e capacidades de atendimento. Observa-se que, a partir de certo ano (1998), por orientação do SUS e possivelmente como forma de facilitar a gestão do sistema - principalmente com relação à realização dos pagamentos - a Secretaria da Saúde passou a agregar às principais unidades dos municípios, várias pequenas unidades de atendimento da periferia e/ou rurais. Dessa forma, um município (Santo Ângelo) que antes contava com 21 PAMs, a partir de 1998 passou a registrar uma unidade. Como fica a respectiva série histórica em um caso como este? Adquire certamente um forte viés ou, em outras palavras, passa a mostrarse inconsistente e, portanto, impossível de ser interpretada. Nessas situações, a única alternativa viável é a da não divulgação da informação até que se encontre uma solução estatisticamente aceitável. ${ }^{12}$ 
Um segundo conjunto de informações trabalhadas pela FEE tem origem na Pesquisa de Emprego e Desemprego (PED), realizada mensalmente no âmbito da Região Metropolitana de Porto Alegre (RMPA), desde $1991 .{ }^{13}$ Os dados oriundos dessa pesquisa continuam representando a única experiência de levantamento direto, de caráter regular, realizada pela FEE nos últimos dez anos. ${ }^{14}$ Neste período, foi acumulado grande volume de informações relativas ao mundo do trabalho na RMPA.

Merece também destaque, pelo volume de informações reunidas, o levantamento de campo - executado pela Associação Riograndense de Empreendimento de Assistência Técnica e Extensão Rural (Emater) e coordenado pela FEE - da situação socioeconômica de pequenos agricultores gaúchos beneficiados com financiamento do PróRural, um programa que conta com recursos do Banco Mundial. A finalidade deste trabalho é avaliar os efeitos sociais e econômicos do programa, uma exigência da entidade financiadora.

Há ainda um tipo especial de informação, de caráter algo distinto das anteriores, representado por um conjunto de indicadores socioeconômicos calculados, com regularidade, pela FEE, de acordo com estatísticas primárias e secundárias disponíveis. Nesse caso, incluem-se os indicadores anuais de produção global e setorial para a economia do Rio Grande do Sul, com destaque para o Produto Interno Bruto. Esse indicador é também calculado para todos os municípios do Estado, mas somente para anos selecionados.

Outro importante indicador calculado pela FEE é o chamado Índice Social Municipal Ampliado (Isma) que objetiva proceder ao ranking dos municípios gaúchos segundo suas condições sociais e econômicas. ${ }^{15}$ Trata-se de um indicador da família do Índice de Desenvolvimento $\mathrm{Hu}$ mano (IDH) concebido e difundido pela Organização das Nações Unidas (ONU). Na verdade, o Isma constitui uma evolução de um projeto anterior desenvolvido na Instituição, o Índice de Desenvolvimento Social (Silveira e Sampaio, 1996). O IDS guarda muitas semelhanças com o IDH, e é calculado com base nas seguintes variáveis: taxa de alfabetização, grau de escolarização, PIB per capita, grau de indigência e taxa de mortalidade infantil.

A disseminação de estatísticas e indicadores tem sofrido uma "revolução" nos últimos tempos, graças às facilidades proporcionadas pelos modernos meios eletrônicos de comunicação. No passado, a divulgação dessa imensa massa de informações era feita sob forma de pesadas publicações em papel, difíceis de serem manuseadas, além de implicarem considerável custo de impressão e de distribuição postal.

A passagem para o suporte em meio magnético passou por uma fase de transição na qual foram largamente utilizados os disquetes. Seu sucessor como mídia favorita de divulgação de informações, o CD-ROM, representou significativo avanço, considerando sua grande capacidade de armazenar dados. Outros pontos favoráveis do CD-ROM e que explicam o seu sucesso são representados por seu fácil manuseio e portabilidade e pelo seu baixo custo. Até mesmo os tradicionais anuários estatísticos de papel da FEE foram substituídos pelo CD-ROM, e organizados no formato de banco de dados, o que facilita a pesquisa e apresentação das variáveis segundo diversas formas de agregação das unidades geográficas.

Outro meio privilegiado de disseminação de informações estatísticas que é largamente utilizado pela FEE é o representado por sua página na $\mathrm{WEB}<\mathrm{www}$.fee.tche.br>. Trata-se de um veículo de alcance universal, o que é comprovado pelo crescente número de visitas registrado mês a mês. Deve ser observado, todavia, que a política de divulgação aqui seguida tem alcance relativamente restrito, uma vez que o site da FEE dá acesso a um conjunto limitado de variáveis dispostas no formato tabela. A evolução natural nesse domínio passa, naturalmente, pela disponibilização on-line das informações no formato de banco de dados, o qual se encontra atualmente em construção e cuja entrada em funcionamento está prevista para 2002.

A produção cognitiva da FEE tem como eixo central a linha de pesquisa dedicada à economia e ao desenvolvimento do Rio Grande do Sul. Como temas "acessórios", mas não menos importantes, são estudados os movimentos do capitalismo em escala nacional e internacional. É óbvio que existem variados desdobramentos setoriais, que surgem como recortes do tema geral, como a economia do Rio Grande do Sul. ${ }^{16}$ Esta produção cognitiva desdobra-se ainda em estudos de curto prazo (análise de conjuntura) e trabalhos que contemplam um horizonte temporal de longo prazo.

A disseminação desse conhecimento é realizada de múltiplas formas. Uma delas, que pode ser considerada convencional, é representada pelo seguinte conjunto de publicações periódicas, em papel:

- Indicadores Econômicos FEE, com periodicidade trimestral;

- Carta Mensal de Conjuntura, com periodicidade mensal;

- Ensaios FEE, com periodicidade semestral. 
As duas primeiras publicações constituem veículos destinados, predominantemente, a divulgar toda a produção do conhecimento sobre a conjuntura socioeconômica local, nacional e internacional. Já a revista Ensaios FEE divulga trabalhos, na forma de artigos, com um caráter mais teórico-conceitual, incorporando textos com maior densidade acadêmica. As duas revistas estão disponíveis para contribuições de autores não pertencentes ao quadro de pesquisadores da FEE, tanto do Brasil como do exterior.

Há dois outros veículos de caráter não periódico, mas seriados. O primeiro deles, denominado Documentos FEE, destina-se à divulgação da produção interna da Instituição, sempre que a mesma exceder o tamanho e não tiver o caráter de um artigo, além de atender ao requisito de representar um produto tecnicamente relevante. O segundo veículo é constituído pela Série Teses e veicula precisamente as teses de responsabilidade de pesquisadores da FEE em seus programas de doutoramento. ${ }^{17}$ Os volumes dessa série assemelham-se aos Documentos FEE no tocante à diagramação e tiragem (média de aproximadamente 100 exemplares).

No passado, a FEE apresentava uma sistemática de publicação dos trabalhos no formato de livros, com tiragens de 600 até 1.000 exemplares. Na época, a Instituição contava com uma unidade gráfica (semi-artesanal) própria, o que significava dispor do controle de todo o processo de produção, desde a elaboração dos estudos até a arte final, impressão e montagem dos documentos. Lamentavelmente, a fúria que presidiu a ação governamental com intuito de reduzir o tamanho do Estado determinou a eliminação dessa fase final do processo produtivo. $\mathrm{Na}$ atualidade, devido aos altos custos privados de impressão, são publicados apenas alguns poucos trabalhos selecionados no formato de livro e que contam com maior tiragem. ${ }^{18}$

A produção cognitiva da Instituição é também difundida por outros meios de divulgação escrita, como é o caso de revistas técnicas de universidades de outras instituições de pesquisa do país. São igualmente canais de divulgação do conhecimento produzido na FEE, de grande capacidade difusora, os meios de comunicação em geral (rádio, jornal e televisão). No caso desses veículos, a disseminação é feita mediante participação de pesquisadores em debates, programas especiais sobre questões socioeconômicas em geral e, em particular, aquelas que são objeto de suas pesquisas. No caso dos jornais, o envolvimento dos pesquisadores pode dar-se por meio de entrevistas ou de artigos assinados.
Por último, um meio facilitador do acesso dos usuários à produção da FEE, adotado recentemente, é a Biblioteca Virtual $(\mathrm{BV})^{19}$ que deverá reunir progressivamente $\mathrm{o}$ acervo da FEE em meio eletrônico, facilitando, assim, a consulta do material via download. A BV é residente no site da FEE, estando, portanto, acessível a todos que podem navegar na Internet.

Ainda outro ponto importante a considerar envolve a identificação de como é formada a demanda por este conjunto de produtos constituído por estatísticas, indicadores e conhecimento sobre a realidade socioeconômica do Rio Grande do Sul? Os usuários desses produtos e serviços são os organismos governamentais, em especial do Estado e dos Municípios, as universidades públicas e privadas (professores e alunos), as entidades de classe (empresariais e de trabalhadores), as empresas privadas, os consultores e organismos não governamentais. Trata-se, portanto, de uma constelação bastante ampla e representativa da sociedade. Nada a ver, é claro, com algo que se aproxime de um consumo de massa, representando, muito mais, uma apropriação seletiva por parte da sociedade e que pode ter, eventualmente, um caráter mais abrangente quando mediado pelos grandes meios de comunicação.

É difícil avaliar quem é o maior usuário das estatísticas, indicadores e conhecimento gerados na FEE. Todavia, percebe-se que os órgãos do Governo do Estado têm aumentado as suas demandas por esse tipo de serviço, assumindo provavelmente o primeiro lugar entre os atuais "clientes" dessa Instituição. Na verdade, o processo recente de aproximação dos organismos públicos, em especial do Executivo, mas também do Legislativo, com as instituições de pesquisa, parece ser um movimento associado à democratização que, felizmente, está em marcha no país. Resulta daí um controle mais amplo das ações de Governo e a exigência de maior eficiência do setor público, tanto do ponto de vista fiscal (Lei de Responsabilidade Fiscal) quanto na gestão das políticas públicas. Este cenário determina a necessidade de conhecer-se com a maior precisão possível a verdadeira amplitude dos problemas sociais e econômicos, bem como passa pela avaliação dos impactos das políticas públicas. Para tanto, é necessário poder contar com uma base consistente de estatísticas e indicadores, além de dispor de estudos e análises acuradas que subsidiem e balizem o processo de tomada de decisões.

Alguns exemplos podem esclarecer melhor a forma e o tipo de demandas, que as Secretarias de Estado e órgãos da Administração Indireta vêm colocando. Nesse sentido, a FEE 
tem realizado todas as estimativas e projeções de população, em idade escolar, por município para que a Secretaria de Educação possa elaborar seu planejamento anual e plurianual de atividades, o que não ocorria no passado.

Um mesmo tipo de trabalho foi realizado para os municípios abrangidos pelo Projeto Pró-Guaíba, vinculado à Secretaria de Coordenação e Planejamento e inserido na área de controle ambiental. Os Gabinetes de Relações Comunitárias e de Orçamento e Finanças, responsáveis pela montagem do orçamento estadual, mediante Orçamento Participativo, são usuários freqüentes das informações encontradas no Anuário Estatístico do Rio Grande do Sul publicado pela FEE. Na verdade, é pelos indicadores municipais contidos no Anuário que são aferidas as regiões e/ou os municípios mais, ou menos, carentes do Estado. São estes os indicadores que permitem efetivamente balizar a aplicação dos critérios estabelecidos no Orçamento Participativo, que é a base para determinar o ranking dos municípios e/ou regiões que serão contemplados com os investimentos do Estado em educação, saúde, saneamento, transportes, etc.

A Secretaria de Desenvolvimento e Assuntos Internacionais desenvolve um programa de apoio aos Sistemas Locais de Produção (clusters) do Estado, como parte da política econômica do Governo. Para tanto, demandou estudo setorial sobre o segmento de autopeças na região de Caxias do Sul que foi elaborado por esta Fundação.

A Secretaria da Agricultura e Abastecimento desenvolve o Projeto RS-Rural, há vários anos, que conta com recursos do Bird. Este projeto tem como objetivo fornecer crédito para pequenos agricultores, de forma a melhorar suas condições gerais de vida. Nesse caso, a FEE é a responsável pelo trabalho de avaliação dos efeitos do programa sobre as propriedades atendidas, ${ }^{20} \mathrm{com}$ medições realizadas no ano zero, no terceiro e no quinto ano, uma exigência do financiador do projeto. Esses são apenas alguns exemplos dos tipos de demandas exercidas sobre a FEE por organismos do Governo Estadual.

As demandas provenientes das Prefeituras concentramse mais na área das estatísticas e indicadores socioeconômicos municipais. Há também inúmeras demandas para os pesquisadores participarem de seminários e discussões com as comunidades locais. Nesse domínio, não tem sido possível o atendimento a todas as solicitações registradas, em função de limitações colocadas por carências do atual quadro de pessoal da Instituição.

Os usuários (professores e alunos) provenientes das universidades e escolas em geral, públicas e privadas, es- tão interessados tanto nas estatísticas e indicadores quanto nos resultados da produção cognitiva da FEE, que são subsídios valiosos para seus trabalhos, em especial sobre a realidade riograndense. Um indicador indireto da participação, no caso dos estudantes, como usuários das informações e do conhecimento armazenado pela FEE pode ser visto no número expressivo de visitantes à biblioteca da Instituição, que representaram em torno de $25 \%$ do total das visitas identificadas em 2001.

As entidades privadas, associações de classe (empresariais e de trabalhadores), ONGs, consultores e o público de não-estudantes representaram em torno de $43 \%$ das visitas à Biblioteca no mesmo ano. Por sua vez, os órgãos públicos (federais, estaduais e municipais) participam com $26,5 \%$ das visitas, o que demonstra o grau de abrangência social do trabalho realizado pela Instituição.

Pode parecer que já se avançou muito no campo das estatísticas, dos indicadores e da produção do conhecimento. Todavia, resta ainda muito a fazer, bastando considerar a quantidade de demandas que seguem afluindo e, o que é mais instigante, o tipo e a qualificação dessas demandas. É o que se pretende discutir na conclusão.

\section{CONSIDERAÇÕES FINAIS}

Talvez seja desnecessário para alguns, mas considerase importante voltar a destacar a importância crescente da informação e do conhecimento no desenvolvimento socioeconômico. Na verdade, esse fato sempre esteve presente no desenvolvimento da humanidade. Todavia, um traço marcante é que após o surgimento do capitalismo essa questão conquistou relevância no modo de vida da sociedade ocidental. As revoluções tecnológicas ocorreram baseadas na melhoria dos sistemas de informação. Esta última, pode ser denominada como a revolução da própria informação e do conhecimento. Nesse sentido, o novo, é que a informação e o conhecimento devem ter, pelo menos, três características. A primeira, é que ela deve representar fielmente o fato. A segunda é que ela possa fluir depressa, velozmente. A terceira, uma conseqüência da segunda, é que ela deve ser a mais atualizada possível, chegar ao usuário praticamente em tempo real, ou o mais instantaneamente possível. O preenchimento dessas três características representaria o ótimo.

Fidelidade, rapidez e tempo real, são as exigências que os usuários têm apresentado aos organismos produtores dessas nobres "mercadorias": a informação estatística e o conhecimento. Um exemplo de demanda, que exige in- 
formações com essas três características, pode ajudar a compreender as dificuldades para atender esse tipo de necessidade do usuário. Órgãos do Governo Estadual têm solicitado informações e indicadores para avaliação das políticas públicas. Ora, esse tipo de aferição compreende pelo menos dois tipos de avaliação. A primeira, é a avaliação da própria implantação do programa, nesse período, em geral as informações necessárias são orçamentárias e/ou do próprio projeto ou política pública, portanto, informações determinadas ex ante. Estes dados, na prática, estão relativamente fora do alcance das Instituições de pesquisa e estatística.

A segunda, refere-se aos efeitos das políticas públicas sobre a realidade socioeconômica. Neste caso, há diversas implicações que dificultam a apuração imediata desses impactos, uma delas é o tempo de maturação do projeto, isto é, o tempo exigido para que os resultados de determinado gasto público sejam visíveis e captados pelos levantamentos correntes. Este tempo é variável de setor para setor e de projeto para projeto. Outra implicação é relativa ao tempo necessário para que as fontes façam o registro primário da informação, que será representativa dos impactos das políticas públicas consideradas. Este período é acrescido de outro tempo para fazer que o dado chegue à instituição estatística que fará a crítica, a organização e a disseminação do mesmo aos usuários. Isso leva, em geral, um tempo maior do que a expectativa dos usuários possa imaginar, o que acaba frustrando seus objetivos.

É possível diminuir, em alguma medida, o período de tempo compreendido entre o momento de geração da informação e de sua distribuição para o usuário, mediante o registro eletrônico no órgão de origem do dado e a transferência imediata à instituição encarregada de preparar a estatística para remetê-la ao usuário final. Esse procedimento beneficiaria, de imediato, os programas cuja maturação ocorre no curto ou médio prazos. Todavia, os projetos de longo prazo de maturação só poderão ser avaliados à medida que a difusão dos impactos possa ser detectada pelas aferições correntes e as informações forem sendo liberadas.

\section{NOTAS}

O autor agradece a leitura atenta e as contribuições do economista Ricardo Brinco a este texto, isentando-o dos equívocos remanescentes.

1. O Resumo Histórico da Estatística no Rio Grande do Sul, de autoria de Albano Gaspar de Oliveira foi originalmente publicado em 1938, tendo sido atualizado por Alvaristo do Amaral Padilha e republicado em 1969 pelo Departamento Estadual de Estatística/Secretaria do Estado.
2. As mudanças registradas foram tanto no formato do órgão quanto na vinculação das atividades desenvolvidas a diferentes secretarias de Estado. Em 1912, por exemplo, a Repartição de Estatística foi desmembrada em três seções pelo então Governador Borges de Medeiros: Estatística Econômica, Estatística Política e Estatística Demográfica.

3. Foi adquirida uma máquina hollerith para facilitar o trabalho de registro das informações.

4. O ano de 1936 revelou-se decisivo para a estatística no Brasil, pois, além da criação do Instituto Brasileiro de Geografia e Estatística, foi estabelecida a Convenção Nacional de Estatística (Decreto $\mathrm{n}^{\circ} 1.022$, de 11/8/1936), pela qual os órgãos estaduais passaram a ser responsáveis pelos levantamentos realizados no âmbito dos municípios.

5. Entre a data de sua criação e a de sua extinção, o DEE esteve vinculado a diversas secretarias: Administração, Economia e da Coordenação e Planejamento, sucessivamente.

6. Na passagem da forma DEE (Administração Direta) para a forma FEE (Administração Indireta) houve uma curta fase de transição que merece ser detalhada. Ao ser extinto o DEE foi substituído pela Superintendência de Estatística e Informática (SEI) (29/5/1972, Decreto $\mathrm{n}^{\circ}$ 21.749) para realizar as mesmas tarefas da estrutura anterior, passando a contar com os novos recursos da informática que começavam a tornar-se disponíveis em nosso meio. Menos de três meses depois, foi criada a Supervisão de Planejamento Global (18/8/1972, Decreto ${ }^{\circ}$ $21.927)$, com a finalidade de realizar estudos sobre a realidade riograndense. Estas duas estruturas foram fundidas seis meses mais tarde, e deram origem à Superintendência de Planejamento Global (Suplag) (mesma sigla, mas com um status mais elevado na SCP). Por fim, no mesmo ano, foi criada a Fundação de Economia e Estatística $\left(13 / 11 / 1973\right.$, Lei $\left.n^{\circ} 6.624\right)$.

7. No passado, as tarefas de organização das informações - confecção de tabelas, gráficos, montagem dos anuários, etc. - eram feitas manualmente. Isto implicava elaboração manuscrita e realização de ciclos sucessivos de conferência, datilografia, nova conferência, etc., só depois sendo os originais encaminhados para a impressão final. Não é difícil avaliar as dificuldades incorridas para gerenciar um processo dessa natureza e o dispêndio de tempo e energia, para gerar um produto, que, muitas vezes, resultava de difícil manuseio.

8. Há dois setores privados que são detentores de grande volume de dados primários. O setor elétrico (distribuição), no Rio Grande do Sul, foi parcialmente privatizado e o das telecomunicações, totalmente privatizado.

9. A Secretaria de Educação Estadual reúne anualmente todas as informações das escolas públicas e privadas no Censo Escolar, não sendo abrangidos apenas os dados relativos ao ensino de Terceiro Grau. A Secretaria da Saúde procede de maneira semelhante, ainda que considere somente os hospitais conveniados com o Sistema Único de Saúde, estando essas informações disponíveis diretamente no site do Data SUS. Já a Secretaria da Fazenda reúne grande volume de informações econômicas organizadas para fazer o cálculo do índice de retorno do ICMS aos municípios e também com vista em subsidiar estudos da própria Secretaria. As instituições da administração indireta, por sua vez, são igualmente geradoras privilegiadas de estatísticas primárias. Os casos mais notáveis são as áreas de saneamento (água e esgoto), energia elétrica e telecomunicações, embora nos anos pós-privatizações, algumas das concessionárias tenham, eventualmente, dificultado o acesso a suas informações.

10. A facilidade proporcionada pelos meios eletrônicos é particularmente notável quando comparada com os mecanismos de transmissão de informações utilizadas até um passado recente, os quais envolviam todo um paciente trabalho de digitação, conferência, organização, etc. até os dados estarem em condições de confiabilidade para divulgação pública.

11. Muitas vezes, é necessário voltar à fonte primária da informação para corrigir ou contornar o problema. Nem sempre é uma tarefa fácil de ser realizada, seja por desinteresse ou má organização dos dados na 
própria origem, seja por carência de recursos humanos qualificados nessa área no âmbito da própria instituição organizadora da informação. Na verdade, a solução mais criativa nesse aspecto passaria por um "processo de qualificação" do quadro técnico que está na origem do dado, o que implica manter uma interação muito próxima e permanente entre informante e recebedor da informação.

12. Uma solução razoável poderia ser mudar a variável representativa para, talvez, "número de atendimentos por unidade administrativa, ou por município", ou ainda, para "capacidade de atendimento instalada". Mesmo assim permanece posta a questão do comprometimento da continuidade da série histórica, salvo se for viável proceder a um reagrupamento os dados também no período anterior à mudança de critério.

13. Pesquisa mensal realizada mediante convênio entre a FEE, Dieese, FGTAS e Fundação SEADE.

14. A FEE realiza, todavia, pesquisas diretas de caráter eventual, em geral para atender necessidades específicas de algum projeto em curso. Foi este o caso, por exemplo, do levantamento de campo realizado no segmento industrial de autopeças de Caxias do Sul, dentro do estudo do Sistema Local de Produção do Setor Automotivo do Rio Grande do Sul.

15. O cálculo do Isma leva em consideração a situação do município em relação a quatro Blocos de Indicadores: Condições de Domicílio e Saneamento, Educação, Saúde e Renda. São 14 variáveis representativas dos quatro Blocos, o que confere um grau de abrangência bastante amplo quando comparado ao IDH e a outros indicadores de condições de vida.

16. Os desdobramentos setoriais referem-se aos clássicos estudos sobre a agropecuária (lavoura e pecuária) e indústria em seus vários segmentos. Outros recortes importantes também são abordados, configurando temas relacionados à problemática regional e urbana, ao mundo do trabalho, às relações internacionais, à política econômica e às finanças públicas.

17. Esta série é retomada após longo período, durante o qual esteve desativada, por conta de problemas relacionados à disponibilidades de recursos financeiros. Convém ressaltar que este problema ainda persiste na atualidade, motivo pelo qual se observa a aplicação de um critério relativamente rígido de escolha das teses a serem publicadas, privilegiando-se as mais relevantes, do ponto de vista técnico e acadêmico.
18. Os dois últimos livros editados pela FEE foram: Impactos sociais e territoriais da reestruturação econômica no Rio Grande do Sul (Castilhos, 1999) e Economia gaúcha e reestruturação nos anos 90 (Fligenspan, 2000)

19. A BV é um projeto concebido e implementado, sob a coordenação da Biblioteca da FEE em parceria com quatro outras Bibliotecas Públicas (Cientec, Emater, Irga e Biblioteca Pública do Estado), reunindo um acervo de aproximadamente 50 mil títulos.

20. O trabalho de avaliação do Programa RS-Rural é realizado em parceria com a Emater, um órgão da própria Secretaria de Agricultura e Abastecimento do Estado.

\section{REFERÊNCIAS BIBLIOGRÁFICAS}

BARBIERI, C.D. et alii. Índice social municipal ampliado. Rio Grande do Sul, FEE, CD-ROM, 2001

CASTILHOS, C.C. et alii. Impactos sociais e territoriais da reestruturação econômica no Rio Grande do Sul. Rio Grande do Sul, Convênio FEE-Finep, 1999.

FLIGENSPAN, F.B. (coord.). Economia gaúcha e reestruturação nos anos 90. Rio Grande do Sul, FEE, 2000.

OLIVEIRA, A.G. de. Resumo histórico da estatística no Rio Grande do Sul. Rio Grande do Sul, DEE, 1938.

SILVEIRA, F.G. e SAMPAIO, M.H.A. Índice de desenvolvimento social (IDS): uma estimativa para os municípios do Rio Grande do Sul. Rio Grande do Sul, FEE, 1996.

José Antônio Fialho Alonso: Presidente da Fundação de Economia e Estatística Sieg Fried Emanuel Heuser; Professor Adjunto Aposentado daUFRGS (presi@fee.tche.br). 